\title{
Pilon kırıklarında fibula tespitinin önemi
}

\author{
The importance of fibula fixation in pilon fractures
}

\author{
Sami Sökücü \\ Baltalimanı Kemik Hastalıkları Eğitim ve Araştırma Hastanesi, Ortopedi ve Travmatoloji Kliniği, İstanbul
}

Tibia pilon kırıkları alt ekstremite kırıklarının \%1'ini ve tüm tibia kırıklarının yaklaşık olarak \%7-10'unu oluşturmaktadır. Bu kırıklar genellikle yüksek enerjili yaralanmalar sonrası meydana gelmekte ve pilon kırıklarının \%85'ine fibula kırığı eşlik etmektedir. Pilon kırıklarının cerrahi tedavisi sonrasında iyi sonuçlar alınabilmesi, eklem redüksiyonun kalitesine, metafizodiyafizer dizilimin sağlanmasına ve erken harekete izin verecek stabil tespite bağlıdır. Pilon kırıklarına eşlik eden fibula kırıklarının tespit edilmesi, uzunluğun, rotasyonun ve dizilim sağlanması açısından önemli olmakla birlikte, yapılan stabil tespit tibia tespitine ek bir stabilite sağlamaktadır. Pilon kırığına eşlik eden fibula kırıklarının tespitinde plak vida konvansiyonel tespit sekli olmakla birlikte, intramedüller implantlar da tespitte kullanılabilmekte ve her iki tespit şeklinin de birbirlerine göre avantajları ve dezavantajları bulunmaktadır. Pilon kırıklarının cerrahi tedavisi sonrasında daha iyi fonksiyonel sonuç almak, tibia yanlış kaynaması ve travma sonrası ayak bileği artrozu ile daha az karşılaşmak için, pilon kırığı ile birlikte görülen fibula kırıklarının tespiti önerilmektedir.

Anahtar sözcükler: pilon; fibula; kırık tespiti
Tibial pilon fractures constitude $1 \%$ of lower extremity fractures and approximately $7-10 \%$ of all tibial fractures. These fractures are often occurs after a high-energy injury and $85 \%$ of pilon fractures are accompanied by fibula fracture. Good results after surgical treatment of pilon fractures depends on the quality of articular reduction, providence of methaphysodiaphyseal alignment and stable fixation that could provide early mobilization. Although detection of accompanying fibula fractures is important in terms of lengthening, rotation and alignment, ensuring stable fixation provides additional stability to the tibia fixation. Although screw-plaque is the conventional method in the fixation of fibula fractures accompanying pilon fractures, intramedullary implants can also be used in the fixation and both techniques have advantages and disadvantages when compared. Fixation of fibula fractures accompanying pilon fractures is recommended in order to get better functional outcomes after surgical treatment of pilon fractures, and experience to a lesser extent tibial malunion and post-traumatic ankle arthritis.

Key words: pilon; fibula; fracture fixation
T ibia pilon kırıkları alt ekstremite kırıklarının \%1'ini, tüm tibia kırıklarının ise yaklaşık olarak \%7-10'unu kapsamaktadır. ${ }^{[1]}$ Bu kırıklar, yüksek enerjili yaralanmalar sonrasında aksiyel ve rotasyonel kuvvetler ile meydana gelmekte, genellikle yumuşak doku sorunları ve aynı taraf fibula kırıkları ile birliktelik göstermektedir. ${ }^{[2,3]}$

Yüksek enerjili yaralanmalar sonrasında meydana gelen pilon kırıklarında, anatomik redüksiyonu zorlaştıran parçalı eklem kırkları ile birlikte gözlenen yumuşak doku yaralanmaları, bu tür kırıkların cerrahi tedavisini zorlaştırmaktadır. Bu kırıkların tedavisi sonrasında iyi sonuç alabilmek için, metafizyel dizilimin ve eklem anatomik redüksiyonunun sağlanması, sonrasında erken harekete izin verecek stabil tespit yapılması gerekmektedir. ${ }^{[4-7]}$

Rüedi ve Allgöwer, pilon kırıklarının cerrahi tedavisinde iyi sonuç alabilmek için, tedavinin birinci basamağında fibula uzunluğunun sağlanması gerektiğini bildirmişlerdir. ${ }^{[8]}$ Babis ve ark., yüksek enerjili yaralanma sonrasında oluşan çok parçalı pilon kırıklarında tedavinin başarısının, kırık tipine, cerrahi tedavi sırasında elde edilen fibula redüksiyonun kalitesine ve kullanılan tedavi metoduna bağlı olduğunu bildirerek, fibula tespitinin önemini vurgulamışlardır. ${ }^{[9]}$ Bu kırıkların tedavisi sonrası gözlenen yumuşak doku sorunlarını

- Illetişim adresi: Doç. Dr. Sami Sökücü, Baltalimanı Kemik Hastalıkları Eğitim ve Araştırma Hastanesi, Rumelihisarı Cad. No: 62 Sarıyer, İstanbul Tel: 0505 - 4511874 e-posta:dr_samis@yahoo.com

- Geliş tarihi: 3 Mayıs $2016 \quad$ Kabul tarihi: 3 Mayıs 2016 
çözmek amacıyla, iki aşamalı tedaviler uygulanmaya başlanmıştır. Bu tedavinin birinci basamağında uzunluğu ve rotasyonu sağlamak amacıyla, fibula kırığı redüksiyonu ve tespiti ile birlikte ayak bileği eklemini geçen eksternal fiksatör uygulaması yapılmakta; ikinci basamağında ise sıklıkla mediyal tarafta gözlenen yumuşak doku sorunları düzeldikten sonra, distal tibia eklem içi kırı̆ıı için açık redüksiyon ve internal tespit uygulanmaktadır. ${ }^{[5,10]}$

Pilon kırıkları ile birlikte görülen fibula kırıklarının tespitinin ek stabilite sağladığı, distal tibiada yanlış kaynama gelişimini azalttığı ve klinik sonuçları iyileştirdiği bildirildiği gibi; pilon kırıklarının tedavisinde fibula tespitinin gerekli olmadığı ve komplikasyon oranlarını arttırdığını iddia eden yayınlar da mevcuttur. ${ }^{[3,11-13]}$

\section{FiBULA TESPITININ STABILITEYE ETKISi}

Tibia kırığı ile birlikte görülen fibula kırıklarının tespitinin alt ekstremite uzunluğunun, rotasyonunun olması gereken pozisyona getirilmesine ve daha stabil bir tespit ile erken yük verilmesine katkı sağladığı teorik olarak bilinmektedir. Fibula tespitinin diğer bir avantajı ise tibiaya uygulanan tespit üzerindeki stresi azaltması ve alt ekstremite normal anatomisinin sağlanması olarak bildirilmiştir. ${ }^{[14]}$

Sağlam bir alt ekstemiteye binen yüklerin yaklaşık olarak \%3-16'sının fibula tarafından iletildiği biyomekanik olarak gösterilmiştir. ${ }^{[15]}$ Weber ve ark., yaptıkları biyomekanik çalışmada, eksternal fiksatör uygulanan tibia kırıklarında fibula tespitinin yapılmasının kırık hattındaki hareketi azalttığını, stabiliteyi arttırdığını ve eksternal fiksatör pinleri üzerine binen stresi azaltarak fiksatör sağkalım süresini uzattığını bildirmişlerdir. ${ }^{16]}$

Fibulası sağlam olan tibia kırıklarında ve tibia tespitine ek olarak fibula tespitinin yapıldığı kruris kırıklarında, fibulanın stabiliteye ek katkı sağladığı bildirilmiştir. ${ }^{[17]}$

\section{FiBULA KIRIĞININ TESPIT ŞEKLi}

Aynı taraf fibula kırı̆ııın eşlik ettiği pilon kırıklarının cerrahi tedavisinde, fibula tespitinde intramedüller kilitli çiviler, plaklar, intramedüller vida ve diğer intramedüller tespit materyalleri kullanılmıştır. ${ }^{[3,11,18]}$

Pilon kırıklarına eşlik eden fibula kırıklarının cerrahi tedavisinde, genellikle standart tedavi şekli olarak, lateral insizyon ile fibula kırığına açık redüksiyon ve plak ile internal tespit uygulanmaktadır. Hastanın yumuşak dokusu lateral insizyona izin verdiği durumlarda fibulaya plak uygulanmasının, kruris kırığı için uzunluğu, rotasyonu sağlayan bir yöntem olduğu ve bu tespitin tibia kırığına uygulanacak olan geçici eksternal tespit için ek bir stabilite sağladığı bildirilmiştir. ${ }^{[3,7,8]}$

Evans ve ark., yaptıkları çalışmada, pilon kırıklarına eşlik eden aksiyel ve rotasyonel stabil fibula kırıklarının tam yivli 3,5 mm'lik vida ile veya $2,5 \mathrm{~mm}$ 'lik humerus intramedüller kılavuz teli kullanılarak intramedüller tespit edilmesini güvenli ve uygulanabilir bir yöntem olarak tarif etmişler; bu tespit sırasında sınırlı disseksiyon yapılmasını, kırık hematomunun dışarı çıkmamış, ek bir yumuşak doku travması yaratmamış ve cerrahi süreyi kısaltmış olmasını, yöntemin avantajları olarak bildirmişlerdir. ${ }^{[11]}$

İntramedüller tespit uygulanan diğer bir çalışmada, Stewart ve ark., intramedüller tespit olarak kilitli Ender çivilerini uyguladıklarını, bu uygulama ile fibula kırıklarında distal rotasyonel stabilite sağladıklarını ve bu uygulamanın pilon kırıklarına eşlik eden aksiyel olarak stabil fibula kırıklarına uygulanabileceğini bildirmişlerdir. ${ }^{[18]}$

Lee ve ark., pilon kırığına eşlik eden fibula kırıklarının tespitinde plak vida tespiti ile intramedüller tespit yöntemlerini karşılaştırmışlar, plak vida ile tespit yapılan hasta grubunda, intramedüller tespit yapılan hasta grubuna oranla redüksiyon kalitesinin daha iyi olduğunu, daha memnun edici sonuç alındığını ve daha az yanlış kaynama olduğunu istatistiksel açıdan anlamlı olarak bildirmişlerdir. ${ }^{[3]}$

Kurylo ve ark., yaptıkları çalışmada, pilon kırığına eşlik eden fibula kırığı olan serilerinde fibulanın plak vida tespiti ile fibulayı tespit etmedikleri iki grubu redüksiyon sonrası dizilim, kaynama olduğundaki dizilim, dizilimdeki değişiklik ve gözlenen komplikasyonlar açısından karşılaştırmışlar; dizilim açısından iki grup arasında anlamlı bir fark tespit edemezken, fibula tespiti yapılan grupta daha fazla oranda komplikasyon gördüklerini belirtmişler ve metafizodiyafizer ayrışması olan, rotasyonel komponenti olmayan pilon kırıklarında fibula tespitinin gerekli olmadığını bildirmişlerdir. ${ }^{[13]}$

\section{FIBULA TESPITININ FONKSIYONEL SONUCA ETKisi}

Cutillas-Ybarra ve ark., pilon kırıklarının genel sağlık bağımlı hayat kalitesi üzerine etkilerini araştırdıkları çaIışmalarında, pilon kırığının genel sağlık bağımlı hayat kalitesi üzerinde uygulanan tedaviden bağımsız olarak belirgin negatif bir etkisinin olduğunu ve bunun fonksiyonel sonucu kötü olarak etkilediğini bildirmişlerdir. ${ }^{[19]}$

Korkmaz ve ark., cerrahi olarak tedavi edilen pilon kırıklı hastalarda sonuçları etkileyen faktörleri araştırdıkları çalışmalarında, kırık tipinin, uygulanan 
cerrahi seçeneğin, redüksiyon kalitesinin pilon kırıklarında fonksiyonel sonuca etkisini araştırmışlar ve Rüedi-Allgöwer Tip 3 kırıkların, fibuladaki dizilim bozukluğu ve kısalığın kötü fonksiyonel sonuca neden olduğunu bildirmişlerdir. ${ }^{[19]}$

Sonuç olarak; fibula kırıklarının eşlik ettiği pilon kırıklarında, distal tibia yanlış kaynama oranını düşürmesi, travma sonrası ankiloz sıklığını azaltması ve klinik fonksiyonel sonucu iyileştirmesi nedeniyle, fibula kırı̆̆ının tespit edilmesi önerilmektedir.

\section{KAYNAKLAR}

1. McFerran MA, Smith SW, Boulas HJ, Schwartz HS Complications encountered in the treatment of pilon fractures. J Orthop Trauma 1992;6(2):195-200.

2. Topliss CJ, Jackson M, Atkins RM. Anatomy of pilon fractures of the distal tibia. J Bone Joint Surg Br 2005;87(5):692-7.

3. Lee YS, Chen SW, Chen SH, Chen WC, Lau MJ, Hsu TL. Stabilization of the fractured fibula plays an important role in the treatment of pilon fractures: a retrospective comparison of fibular fixation methods. Int Orthop 2009;33(3):695-9. Crossref

4. Watson JT, Moed BR, Karges DE, Cramer KE. Pilon fractures. Treatment protocol based on severity of soft tissue injury. Clin Orthop Relat Res 2000;(375):78-90.

5. Sirkin M, Sanders R, DiPasquale T, Herscovici D Jr. A staged protocol for soft tissue management in the treatment ofcomplex pilon fractures. J Orthop Trauma 2004;18(8 Suppl):S32-8.

6. Chen $\mathrm{SH}, \mathrm{Wu} \mathrm{PH}$, Lee YS. Long-term results of pilon fractures. Arch Orthop Trauma Surg 2007;127(1):55-60.

7. Harris AM, Patterson BM, Sontich JK, Vallier HA. Results and outcomes after operative treatment of high-energy tibial plafond fractures. Foot Ankle Int 2006;27(4):256-65.

8. Rüedi TP, Allgöwer M. Fractures of the lower end of the tibia into the ankle joint. Injury 1969;1(2):92-9. Crossref
9. Babis GC, Vayanos ED, Papaioannou N, Pantazopoulos T. Results of surgical treatment of tibial plafond fractures. Clin Orthop Relat Res 1997;(341):99-105.

10. Patterson MJ, Cole JD. Two-staged delayed open reduction and internal fixation of severe pilon fractures. J Orthop Trauma 1999;13(2):85-91.

11. Evans JM, Gardner MJ, Brennan ML, Phillips CJ, Henley MB, Dunbar RP. Intramedullary fixation of fibular fractures associated with pilon fractures. J Orthop Trauma 2010;24(8):491-4. Crossref

12. Williams TM, Marsh JL, Nepola JV, DeCoster TA, Hurwitz SR, Bonar SB. External fixation of tibial plafond fract ures: is routine plating of the fibula necessary? J Orthop Trauma 1998;12(1):16-20.

13. Kurylo JC, Datta N, Iskander KN, Tornetta P 3rd. Does the Fibula Need to be Fixed in Complex Pilon Fractures? J Orthop Trauma 2015;29(9):424-7. Crossref

14. Morrison KM, Ebraheim NA, Southworth SR, Sabin JJ, Jackson WT. Plating of the fibula: its potential value as an adjunct to external fixation of the tibia. Clin Orthop Relat Res 1991;(266):209-13.

15. Lambert $\mathrm{KL}$. The weight bearing function of the fibula. A strain gauge study. J Bone Joint Surg Am 1971;53(3):507-13.

16. Weber TG, Harrington RM, Henley MB, Tencer AF. The role of fibular fixation in combined fractures of the tibia and fibula: a biomechanical investigation. J Orthop Trauma 1997;11(3):206-11.

17. Gotzen L, Haas N, Hütter J, Köller W. Die Bedeutung der Fibula fur die Stabilitat der Plattenosteosynthese an der Tibia. Unfallheikunde 1978;81(5):409-16.

18. Stewart CM, Kiner D, Nowotarski P. Intramedullary nail fixation of fibular fractures associated with tibial shaft and pilon fractures. J Orthop Trauma 2013;27(5):e114-7. Crossref

19. Cutillas-Ybarra MB, Lizaur-Utrilla A, Lopez-Prats FA. Prognostic factors of health-related quality of life in patients after tibial plafond fracture. A pilot study. Injury 2015;46(11):2253-7. Crossref 